\title{
A study of transferability of atomic background on EXAFS spectra of simple gaseous compounds of As
}

\author{
Alojz Kodre, Rok Preseren, Iztok Arčon, Jana Padežnik Gomilšek and Michael \\ Borowski
}




\section{A study of transferability of atomic background on EXAFS spectra of simple gaseous compounds of As}

\section{Alojz Kodre, ${ }^{a b^{*}}$ Rok Prešeren, ${ }^{a}$ Iztok Arčon, ${ }^{c b}$ Jana Padežnik Gomilšek, ${ }^{d}$ and Michael Borowski ${ }^{e}$}

${ }^{a}$ Faculty of Mathematics and Physics, Jadranska 19, SI-1000 Ljubljana, Slovenia, 'Joz ef Stefan Institute, Jamova 39, POB 3000, SI-1001 Ljubljana, Slovenia, 'Nova Gorica Polytechnic, Vipavska 13, SI-5000 Nova Gorica, Slovenia, ${ }^{d}$ Faculty of Mechanical Enginnering, Smetanova 17, SI-2000 Maribor, Slovenia, ${ }^{\circ}$ European Synchrotron Radiation Facility (ESRF), BP 220, 38043 Grenoble Cedex, France.

Email:alojz.f.kodre@ijs.si

From EXAFS spectra of As and $\mathrm{As}_{2} \mathrm{O}_{3}$ vapors and arsine gas $\mathrm{AsH}_{3}$ the $a b$ initio calculated structural signal is removed. The remainders comprise small absorption edges due to shake-up channels involving electrons from $3 \mathrm{~d}$ or $3 \mathrm{p}$ subshell. With enhanced resolution, the edges reveal a fine splitting and a varying contribution of resonance channels, due to individual molecular energy-level structure of the samples. On the resolution level appropriate for routine EXAFS analysis the remainders coincide, representing a unique and transferable atomic absorption background for the range of As valence states spanned by the samples.

\section{Keywords: Atomic background transferability, As K-edge} EXAFS, As, $\mathrm{As}_{2} \mathrm{O}_{3}$ and $\mathrm{AsH}_{3}$ gases

\section{Introduction}

In precision EXAFS structure determination, the conventional spline reconstruction of low-wavenumber components cannot satisfactorily describe non-structural, intra-atomic effects. In particular, sharp features such as small resonances and absorption edges, introduced into absorption spectra by multielectron excitations, contribute nonnegligible high-wavenumber components which can interfere with the structural signal (Frahm et al., 1984; Kochur et al., 1986; Kodre et al., 1994; Chaboy et al., 1994; Kodre et al., 1995; Filipponi, 1995; Filipponi \& Di Cicco, 1995; Kodre et al., 1997; Arčon et al., 1997; Padežnik Gomilšek et al., 1999). Thus, a true atomic absorption background ( $\mathrm{AAB}$ ) from an independent measurement or calculation is required. Some of the scarce available data on AAB is constructed from semi-empirical models (Di Cicco, 1995; Di Cicco et al., 1996; Arčon et al., 1997), some is recovered from standard EXAFS samples (Li et al., 1992; D’Angelo et al., 1993; Bridges at al., 1995; D'Angelo et al., 1995; D'Angelo et al., 1996; Padežnik Gomilšek et al., 1999-a). A similar approach has been exploited in AXAFS (atomic EXAFS) investigations (Holland et al., 1978; Rehr et al., 1994). For a very small number of elements AAB can be measured directly and with high accuracy on monatomic gaseous samples (Schaphorst et al,. 1993; Filipponi et al., 1993, Kodre et al., 1997, Prešeren et al., 1996; Prešeren et al. 1999; Prešeren \& Kodre, 1999-a). It has been shown that simple molecular gases can also be used for the purpose (D'Angelo et al., 1993; Prešeren et al., 2000). Exploiting this approach we have devised a direct test of the transferability of $\mathrm{AAB}$ of an element. The concept of transferability is generally assumed, in view of the intra-atomic origin of the AAB, but it has hardly been supported by convincing experimental evidence. (However, in the AXAFS interpretation, the transferability is limited to similar environments of the atom.) In this study, we compare $\mathrm{AAB}$ extracted from three gaseous compounds of arsenic.

\section{Experiment}

Arsine, $\mathrm{AsH}_{3}$, is a stable gas at room temperature. A $60 \mathrm{~mm}$ long glass absorption cell with kapton windows was filled with $40 \mathrm{kPa}$ of arsine, yielding absorption $\mu \mathrm{d} \sim 1.7$ at the As $\mathrm{K}$ edge. Arsenic trioxide, $\mathrm{As}_{2} \mathrm{O}_{3}$, sublimates at temperatures above $300^{\circ} \mathrm{C}$. As its vapor reacts slowly with most of conventional cell and window materials, a sample of $12 \mathrm{mg}$ of $\mathrm{As}_{2} \mathrm{O}_{3}$ was sealed in a $200 \mathrm{~mm}$ long absorption cell of Duran glass with $0.3 \mathrm{~mm}$ thick windows of the same material. The absorption in the windows contributed $\mu \mathrm{d} \sim 2$, and the absorption in the sample, when completely vaporized at $320^{\circ} \mathrm{C}, \mu \mathrm{d} \sim 1.7$. At this temperature, it took $\sim 1$ hour before the oxide reacted with glass appreciably.

Elemental arsenic is also known to sublimate above $500^{\circ} \mathrm{C}$. At this temperature, it reacts vigorously with standard high-temperature cell and window materials, stainless steel, quartz, and glass. In the latter, however, the reaction is relatively slow, so that a single spectrum of 20 min duration could be recorded. A $300 \mathrm{~mm}$ long Duran cell with $0.3 \mathrm{~mm}$ thick Duran windows was used, operated at $490^{\circ} \mathrm{C}$, yielding $\mu \mathrm{d} \sim 0.3$ at the As K edge.

The As $\mathrm{K}$ edge absorption spectra of $\mathrm{As}_{2} \mathrm{O}_{3}$ vapor and $\mathrm{AsH}_{3}$, were measured at BM 29 of the European Synchrotron Radiation Facility (ESRF) in Grenoble, France. The absorption spectrum of As vapor was measured at the $\mathrm{X} 1$ station of the Doris ring in Hamburger Synchrotronstrahlungslabor HASYLAB at Deutschen ElektronenSynchrotron DESY (Hamburg, Germany). At both beamlines a $\mathrm{Si}(311)$ fixed-exit double-crystal monochromator was used. The resolution at $12 \mathrm{keV}$ was $0.8 \mathrm{eV}$ at $\mathrm{BM} 29$ and $1.5 \mathrm{eV}$ at $\mathrm{X} 1$. Harmonics were effectively eliminated by detuning the monochromator crystal using a stabilization feedback control. Ionization cells filled with argon were used to detect the incident flux of the monochromatic x-ray beam and the flux transmitted through the sample.

The absorption cell of arsine was equipped with a side chamber into which the gas could be frozen in situ to obtain a precision reference measurement of the window transmission and energy dependence of detector efficiency. Reference spectra for arsenic trioxide and elemental arsenic were taken on the cells at room temperature before heating.

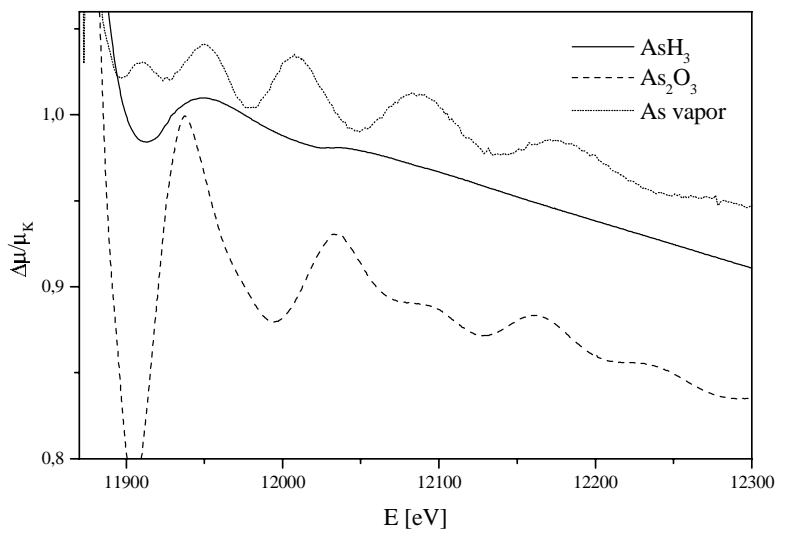

Figure 1

The normalized As $\mathrm{K}$ edge absorption spectra of gaseous $\mathrm{AsH}_{3}$ (solid line), $\mathrm{As}_{2} \mathrm{O}_{3}$ vapor (dashed line) and As vapor (dotted line). The spectra are slightly displaced along vertical axis for clarity. 


\section{Experimental results}

The quality of the spectra (Fig. 1) differs considerably between the three compounds, as a consequence of different experimental conditions. The stable gas arsine, in a cell with kapton windows, gives a spectrum comparable to the state-of-the-art noble-gas spectra. With superposition of 10 independent scans, the signal-tonoise ratio of $4 \times 10^{4}$ is achieved. The resolvable level of detail is very high as shown in the derivative spectra in the insets of Fig. 2. The structural signal, resulting from the photoelectron scattering on the $\mathrm{H}$ neighbors is smooth and relatively weak so that the sharp features of the As AAB are plainly visible.

The quality of the spectrum of arsenic oxide is appreciably diminished by the strong absorption in the windows. The structural signal of $\mathrm{O}$ and As neighbors is prevailing, so that the features of the $\mathrm{AAB}$ cannot be readily observed. The noise level is larger than in arsine by an order of magnitude.

The noise level in the spectrum of arsenic vapor is larger still, of the order of $10^{-3}$, mainly due to the lower density and the absorption in glass windows. The spectrum exhibits a strong structural signal of As neighbors since the vapor contains $\mathrm{As}_{4}$ molecules.

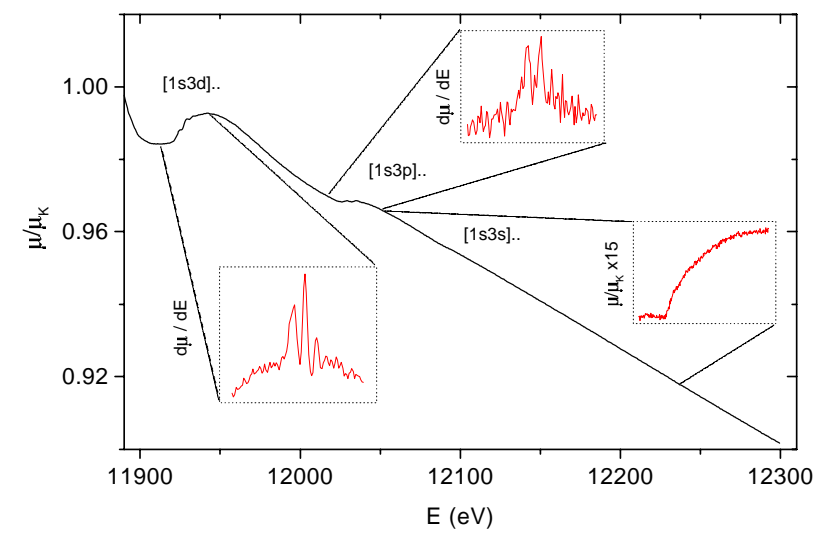

Figure 2

The normalized As $\mathrm{K}$ edge absorption spectrum of $\mathrm{AsH}_{3}$ gas. The insets show derivatives of the spectrum in the region of $1 \mathrm{~s} 3 \mathrm{~d}$ and $1 \mathrm{~s} 3 \mathrm{p}$ multielectron photoexcitation and a magnified region of the $1 \mathrm{~s} 3 \mathrm{~s}$ excitation.

\section{Analysis}

In order to extract $\mathrm{AABs}$, the structural signal for all three molecules was modeled in FEFF 6 code (Rehr et al., 1992; Stern et al., 1995) and removed from the spectra. For $\mathrm{AsH}_{3}$, it is possible to construct the EXAFS signal $a b$ initio from known interatomic distances and angles (Greenwood \& Earnshaw, 1984), scattering factors, and vibrational modes of the molecule (Cyvin, 1968). The ab-initio construction is imperative since there is little possibility of adjusting the FEFF model parameters by a best-fit procedure to the indinstinct structural signal in the measured spectrum.

For $\mathrm{As}_{2} \mathrm{O}_{3}$ vapor, the conventional semiempirical FEFF model is employed: the geometry of the molecule, a tetrahedron of As atoms with $\mathrm{O}$ atom links along edges, actually corresponds to the dimer $\mathrm{As}_{4} \mathrm{O}_{6}$. Positions of the atoms and the scattering data are introduced ab initio. The Debye-Waller factors, however, are determined by best-fit to the well-resolved structural signal. The model contribution of the first (O) and the second (As) neighbors, together with some weak higher order-scattering, explains the two major peaks in the FT spectrum remarkably well. However, after removal of the model signal, the remaining atomic background still shows a

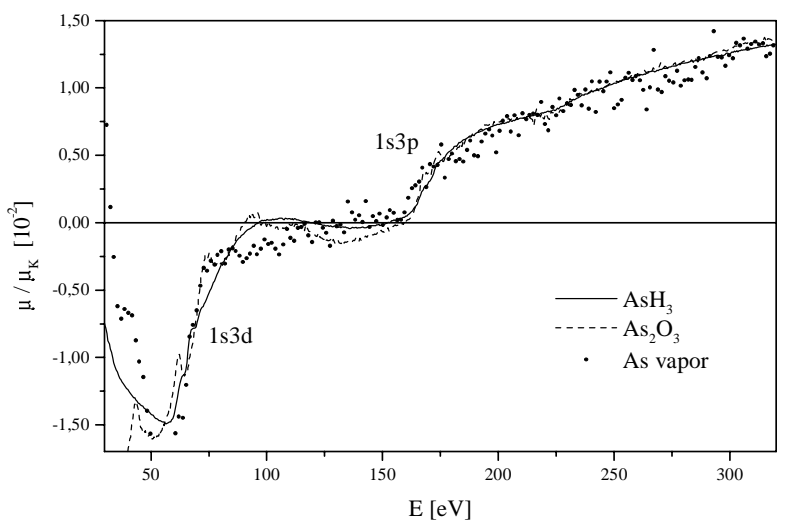

\section{Figure 3}

The comparison of $\mathrm{AAB}$ extracted from absorption spectra of three As molecules. The common energy scale is defined relative to the respective energies of the As K-edge.

small contribution of short-wave components that cannot be accounted for by the scattering paths within the molecule. They are mostly explained as an absorption signal from a very small quantity of crystalline $\mathrm{As}_{2} \mathrm{O}_{3}$, adsorbed on the cell windows. Indeed, with addition of scattering paths in solid $\mathrm{As}_{2} \mathrm{O}_{3}$ to the model, the qualityof-fit-measure in the FEFFIT procedure, the r-factor of 0.001 is obtained.

For As vapor, the same semiempirical approach is employed, with an additional modification. According to chemical data (Cyvin, 1968; Greenwood \& Earnshaw, 1984), the As molecule in the vapor is tetraatomic in the range of temperatures in the experiment. The FEFFIT procedure, however, gives an essential improvement in the fit at the non-integer number of neighbors $\mathrm{N}=3.8$, indicating a mixture of tetraatomic molecules and larger aggregates.

\section{Conclusions}

The AABs of the three As molecules are shown in Fig. 3. Although they differ appreciably in quality, the $\mathrm{As}_{2} \mathrm{O}_{3}$ background ridden by residual shortwave components and the As background by the large noise, the three spectra are clearly identical with relative deviations below $3 \times 10^{-3}$ and on the level of resolution of routine EXAFS analysis, so that a unique As atomic background can be defined for most practical purposes. The non-transferable part of $\mathrm{AAB}$, due to alternative mechanisms such as AXAFS, is thus limited to a smooth contribution with amplitude of deviations mentioned above.

The sharp features of the background have been identified as fingerprints of two-electron excitations (Prešeren, 2000-a): indeed, they can be decomposed into contributions of resonant and shake channels for the two major excitation groups, $1 \mathrm{~s} 3 \mathrm{~d}$ and $1 \mathrm{~s} 3 \mathrm{p}$ (Fig. 4). The energies of the channels lie within a few $\mathrm{eV}$ of energies calculated by a Dirac-Fock relativistic self-consistent model of the As atom. For an atomic calculation, the mismatch is relatively large. It is caused by the fact that the excited states are molecular in character: the hybridization of electronic orbitals in a molecule introduces a shift of a few $\mathrm{eV}$ from the corresponding atomic energy levels which are modelled in the self-consistent calculation.

The complete decomposition of the sharp $\mathrm{AAB}$ features of $\mathrm{AsH}_{3}$ and $\mathrm{As}_{2} \mathrm{O}_{3}$ shown in Fig. 4 testifies that they arise entirely from the internal atomic dynamics, namely, the collective response to the photoexcitation. There is another remarkable fact in support of the finding: the parameters by which the components are described energies, amplitudes and linewidths - are identical within experimental error for both molecules, with exception of the width 
parameter. The smaller effective width of resonances in the oxide spectrum accounts for their relative prominence. Thus, the transition probabilities which define the shape of the jumps in $A A B$ are essentially the same for both molecules. The observed small differences between the two sharp $\mathrm{AAB}$ features can be attributed merely to different widths of the lowermost unoccupied molecular levels.
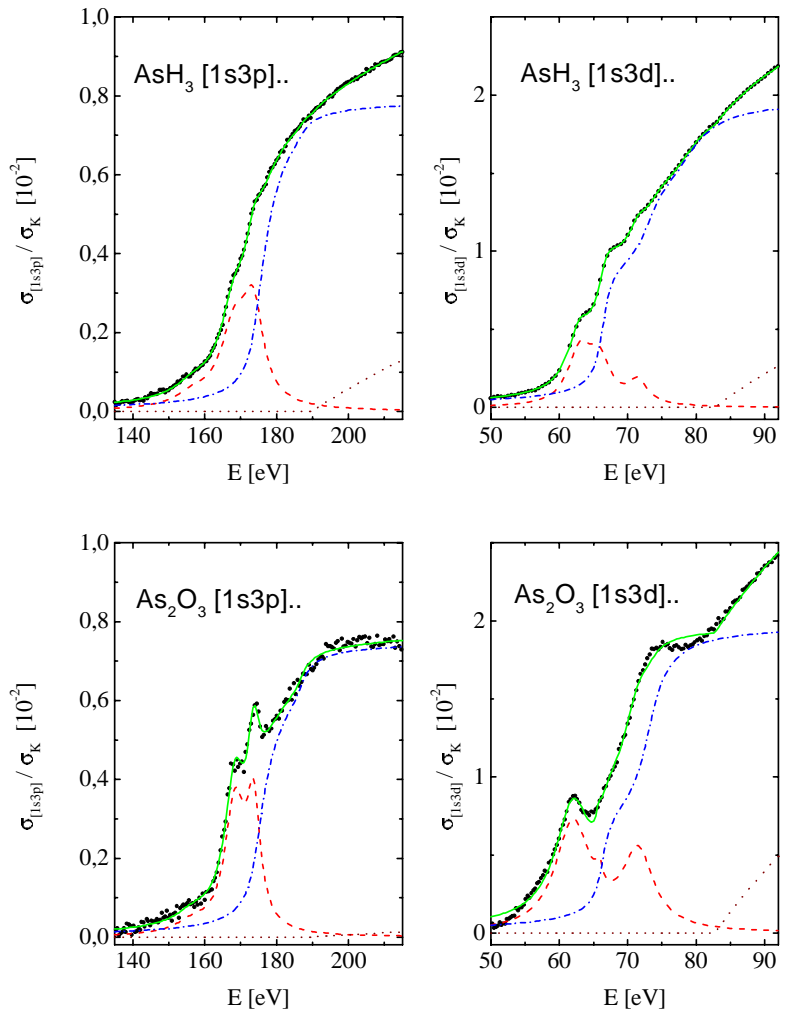

\section{Figure 4}

The [1s3p] and [1s3d] multielectron photoexcitation features in $\mathrm{AsH}_{3}$ and $\mathrm{As}_{2} \mathrm{O}_{3}$ absorption spectra decomposed into contributions of resonant (dashed line), shake-up (dot-dashed line) and shake-off channels (dotted line). Sum (solid line) and experiment (bullets).

Acknowledgment: The study is supported by Internationales Büro des BMBF, Germany and Ministry of Sciences and Technology, Slovenia. L. Troeger from HASYLAB provided expert advice on beamline operation. The experiment at the BM29 beamline of ESRF was performed under proposal No. HE-375.

\section{References}

Arčon, I. \& Kodre, A. (1997). J. de Physique IV France 7, Coll. 2, Suppl. JP III, C2-223 - C2-224.

Bridges, F., Booth, C.H. \& Li, G. G. (1995). Physica B 208\&209, 121-124.
Chaboy, J., Marcelli, A. \& Tyson, T. A. (1994-I). Phys. Rev. B 49, 1165211661.

Cyvin, S. J., (1968). Molecular vibrations and Mean Square Amplitudes, Amsterdam, Netherlands: Elsevier.

D’Angelo, P., Di Cicco, A., Filipponi, A. \& Pavel, N. V. (1993). Phys. Rev. A 47, 2055-2063.

D’Angelo, P., Di Noia, A., Giglio, E., Magnoni, M. \& Pavel, N. V. (1995). J. Phys. Chem. 99, 5471-5480.

D’Angelo, P., Nolting, H. -F. \& Pavel, N.V. (1996). Phys. Rev. A 53, 798805.

Di Cicco, A. (1995). Physica B 208\&209, 125-128.

Di Cicco, A., Filipponi, A., Itie, J. P. \& Polian, A. (1996). Phys. Rev. B 54, 9086-9098.

Filipponi, A., Ottaviano, L. \& Tyson, T.A. (1993). Phys. Rev. A 48, 20982101.

Filipponi, A. (1995). Physica B 208\&209, 29-32.

Filipponi, A. \& Di Cicco, A., (1995). Phys. Rev. A 52, 1072-1078.

Frahm, R., Haensel, R. \& Rabe P. (1984). J. Phys. F: Met. Phys. 14, 10291046.

Greenwood, N. N. \& Earnshaw, A. (1984). Chemistry of the elements, Oxford, UK: Butterworth - Heinemann LTD.

Holland, B. W., Pendry, J. B., Pettifer, R. F. \& Bordas, J. (1978). J. Phys. C 11, 633-642.

Kochur, A. G., Nadolinsky, A. M. \& Demekhin, V.F. (1986). J. de Physique, Coll. C8, C8-83 - C8-87.

Kodre, A., Arčon, I., Hribar, M., Štuhec, M. \& Villain, F. (1994).

J. de Physique C-9, suppl. III Vol 4, 397-400.

Kodre, A., Arčon, I., Hribar, M., Štuhec, M., Villain, F., Drube, W. \& Troeger, L. (1995). Physica B 208\&209, 379-380.

Kodre, A., Arčon, I. \& Frahm, R. (1997). J. de Physique IV France 7, Coll. 2, Suppl. JP III, C2-195 - C2-198.

Kodre, A., Padežnik Gomilšek, J., Arčon, I. \& Prešeren, R. (1999). J. Synchrotron Rad. 6, 306-307.

Li, G., Bridges, F. \& Brown, G. S. (1992). Phys. Rev. Lett. 68, 1609-1612.

Padežnik Gomilšek, J., Kodre, A., Arčon, I., Loireau-Lozac'h, A.M. \& Benazeth, S. (1999). J. Synchrotron Rad. 6, 304-305.

Padežnik Gomilšek, J., Kodre, A., Arčon, I., Loireau-Lozac'h, A. M. \& Benazeth, S. (1999-a). Phys. Rev. A 59, 3078-3081.

Prešeren, R., Arčon, I., Mozetič, M., Kodre, A. \& Pregelj, A. (1996). Nucl. Instrum. Methods Phs. Res. B 111, 161-162.

Prešeren, R., Kodre, A., Arčon, I., Padežnik Gomilšek, J. \& Hribar, M. (1999). Nucl. Instrum. Methods Phs. Res. B 149, 238-240.

Prešeren, R. \& Kodre, A. (1999-a). Rad. Phys. And Chem. 55, 363-366.

Prešeren, R., Kodre, A., Arčon, I. \& Borowski, M. (2000). This conf.

Prešeren, R. (2000-a). Dissertation, Faculty of mathematics and physiscs, University of Ljubljana, Slovenia.

Rehr, J. J., Booth, C. H., Bridges, F. \& Zabinsky, S. I. (1994). Phys. Rev B 49, 12347-12350.

Rehr, J. J., Albers, R. C. \& Zabinsky, S. I. (1992). Phys. Rev Lett. 69, 33973400 .

Schaphorst, S. J., Kodre, A. F., Ruscheinski, J., Craseman, B., Aberg, T., Tulkki, J., Chen, M.H., Azuma, Y. \& Brown, G.S. (1993). Phys. Rev. A 47, 1953-1966. (and references therein)

Stern, E.A., Newville, M., Ravel, B., Yacoby, Y. \& Haskel, D. (1995). Physica B 208\&209, 117-120. 